\title{
ROMANIAN
}

NEUROSURGERY

Vol. XXXIV | No. 3 September 2020

Spinal cord injury without radiologic abnormalities in a 4-years old boy.

A case report

Sani Madjiri Laminou,

Ibrahim Assoumane,

Adamou Harissou,

Sanoussi Samuila,

Abarchi Habibou,

Smida Mahmoud 


\section{Spinal cord injury without radiologic abnormalities in a 4-years old boy. A case report}

\section{Sani Madjiri Laminou ${ }^{1}$, Ibrahim Assoumane ${ }^{2}$, Adamou Harissou ${ }^{3}$, Sanoussi Samuila ${ }^{4}$, Abarchi Habibou $^{5}$, Smida Mahmoud ${ }^{1}$}

\author{
${ }^{1}$ Department of Paediatric Surgery, Tunis, TUNISIA \\ 2 Department of Neurosurgery, Reference Hospital Maradi, NIGER \\ REPUBLIC \\ 3 Department of General Surgery, Zinder National Hospital, NIGER \\ REPUBLIC \\ ${ }^{4}$ Department of Neurosurgery, Niamey National Hospital, NIGER \\ REPUBLIC \\ 5 Department of Paediatric Surgery, Lamordé National Hospital, \\ Niger REPUBLIC
}

\section{ABSTRACT}

In this study, we describe a 4-year-old boy with a head, cervical, and left shoulder injury following the reception of a heavy metallic door on his left side that resulted in SCIWORA.

SCWORA is defined as spinal cord injury without $x$ rays or CT scans lesions but can be detectable on RMI scans. SCIWORA follows trauma, sometimes trivial. The management consists of immobilization and nursing. The clinician should be aware of this entity. We are reporting the management of a four years old boy.

\section{INTRODUCTION}

The term SCIWORA (spinal cord injury without radiographic abnormality) was coined by Pang and Wilberger in 1982 [1].

It is defined as objective signs and symptoms of myelopathy with no evidence of fracture or ligamentous instability on plain spine radiographs and tomography. This definition excluded all MRI findings and any injuries from open or penetrating trauma, electric shock and all related to congenital spinal anomalies. Ergun et al [2] highlighted the patho-physiological basis of SCIWORAs. The anterior spinal artery receives its main blood supply from vertebral arteries. Hyper motion effect of the spinal cord during trauma may provoke a temporary occlusion or spasm of the vertebral arteries, the anterior spinal artery

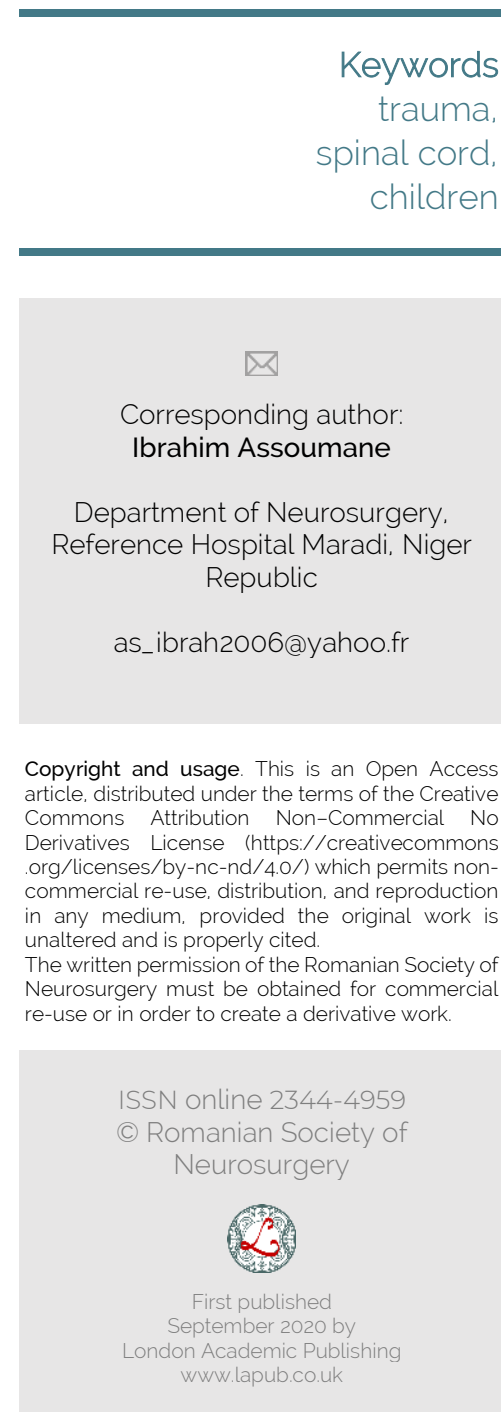


or the distal branches of the central sulcus arteries leading to a spinal cord infarction.

Other anatomic factors considered by Ergun include the vertebral alignments of cervical spine; the planes of the facet joint which are more horizontal, the anterior portions of vertebral bodies are weighed forward, the uncinate processes are flat, the under developed musculature of children's neck and the heavy head. These above predispose the cervical column of children to flexion, extension or longitudinal distraction injuries. Trigylidas et al [3] conclude that the innate ligamentous laxity of the pediatric spine may protects it from injury in minor trauma, but these same protective features expose them to permanent injuries in high intensity trauma. Here we are reporting a case of SCIWORA in a 4years old boy.

\section{OBSERVATION}

A 4 years old boy polytraumatism referred from Poudriere general hospital with head injury with initial loss of consciousness, cervical trauma and left shoulder trauma. The patient was stamped by a heavy metallic door on the head, neck and the left shoulder. At admission the Glasgow scale was normal, left mydriasis, bilateral palpebral oedema. He was tetraplegic spontaneous mobilization of the cervical spine, lost of sensation of the right hemi body and reduced sensation of the left side. The ROT are absents in the 4 limbs, no Babinski sign, cremasteric sign is abolished and the anal sphincter was not tonic. The lesionnel level was the mammary line. The standard radiograph of the head, the cervical spine was normal [fig1]; the left shoulder $X$ ray revealed a mid-shaft clavicle fracture. A cerebrospinal CT scan was performed, but was normal.

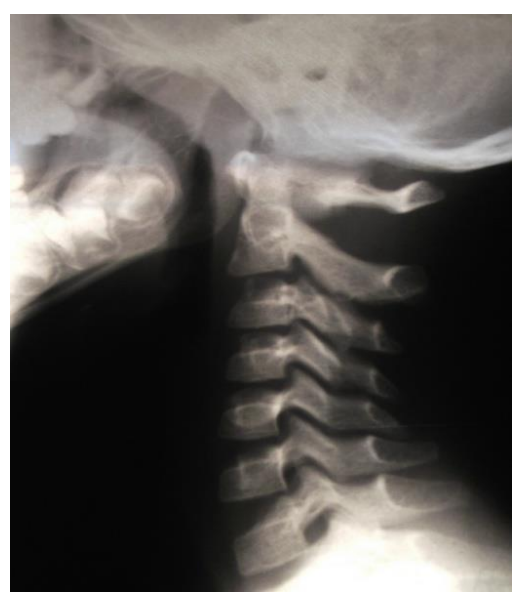

Figure 1. Lateral $X$ ray of the cervical spine, no lesion observed.
We requested a neurologic view. The patient returned to us with same examination findings. The diagnosis of SCIWORA was made the patient placed in ICU, nursing and resting was consigned and a cerebrospinal RMI was performed. It revealed no cerebral lesion but there was thickening of the spinal cord from C3 to C7 with narrowing of the perimedullar space [fig 2].

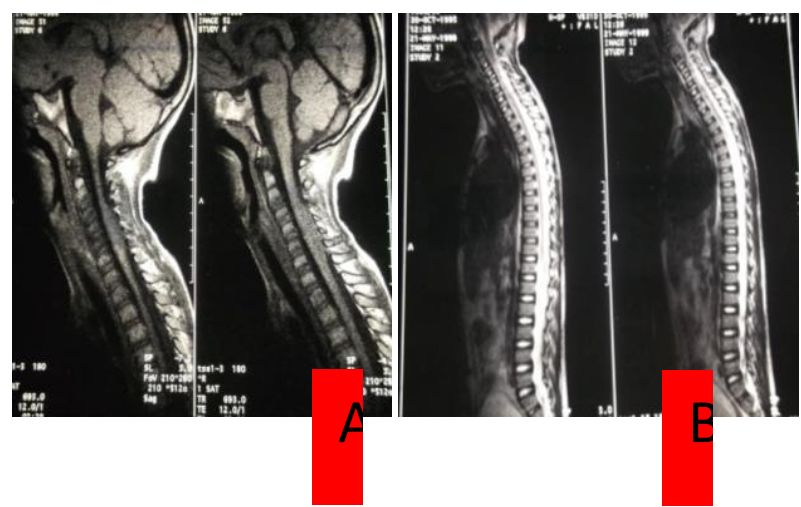

Figure 2. Cervical spine RMI Showing cord thickening from C3 to C7; no other lesion was recorded. A: Sagital T1; B: Sagital T2.

\section{DISCUSSION}

SCIWORA accounts for $1-10 \%$ of the spinal cord injury in children. Gregory et al [5] reported $0.08 \%$ cases in a multicentric study on about 34069 patients., SCIWORA is more common in children than adult with literature reports of 13 to $19 \%$ and 10 to $12 \%$ of children and adult spinal cord injuries respectively $[6,8,9]$

The trauma causing SCIWORAs may not be of high intensity only, it may be trivial also. This is widely illustrated in the literature. Trigylidas [3] found 51\% cases of sport related injuries, $36 \%$ of RTA and 13\% of falls. Ergun et al reported a 12-year-old girl who slipped on her way home from a volley ball match and developed SCIWORA. Our patient was stamped by a heavy door. Injury to the cervical spine is much more common than the thoracic and lumbar spine. The upper cervical spine $(C 2, C 3)$ is more prone to flexion injuries. Snoek [4] reported that traction injuries may be common in thoracic and lumbar spine.

Clinical features classically include neurological deficit (decrease reflexes and power, reduced sensations below the level of the lesion, reduced anal tone and loss of bladder control), torticolis [4]. These findings correlate with our patient. The IRM findings ranged from spinal cord contusion [2], central disc 
herniation [2, 5], paramedian disc herniation [5], spinal cord stenosis [5], ligamentous injury spinal cord edema [4] and hemorrhage [4]. The corresponding standard radiographs and CT scans were all normal. We found cord edema in IRM reports, Lammertse et al [7] coined IRM as the gold standard in diagnosis of spinal cord injuries. The outcome of SCIWORA may be good or devastating to the patients and their families'. The patient in our report sustained permanent injury. Snoek reported a good prognosis in a child who sustained bifocal SCIWORA following RTA. The outcome is independent the intensity of the trauma. It would rather be influenced by the patient age and the level of the lesion. The development of the cervical spinal musculator reaches it fulcrum by the age of 8 . Lesions below 8 years of age may have poor prognosis especially associated with upper cervical injuries [2]. Above 8 years the spinal architecture is approaching that adult, thus lesions occur in lower spine under high velocity trauma.

\section{CONCLUSION}

SCIWORA is a disease entity of children and adult. Following injury, a high index of suspicion is necessary in injured patients in whom movement of all limbs is not seen. MRI is standard diagnosis and the outcome depends on the spinal injury.

\section{REFERENCES}

1. D. Pang and J. E. Wilberger, "Spinal cord injury without radiographic abnormalities in children," Journal of Neurosurgery1982, vol.57, no. 1, pp. 114-129.

2. Ergun and W. Oder, "pediatric care report of spinal cord injury without radiologic anomalies: case report and a review of literature, «spinal cord 2003, vol 41, pp .249253.

3. Trigylidas.T, Yuh.S.J, Vassilyadi.M, Matzinger.M.A, Mikrogianakis.A, "spinal cord injuries without radiologic anomalies at two pediatric trauma centers in Ontario ", pediatric neurosurgery 2010; 43:283-289.

4. Snoek .K.G, Jacobson .M. A.B.VanAs,"Bifocal spinal cord injuries without radiographic anomalies in a 5years old boy: case report "case reports in pediatrics 2012.

5. Gregory.WHendey, Allan.BWolfson, William.R Mower, Jerome. $\mathrm{R}$ Hoffman «spinal cord injury without radiologic abnormality: result of the National Emergency $X$ radiographic utilization study», the journal of trauma, injury and critical care 2002; 53, 1-4.

6. Kivanc Atesok, Nobuhiro Tanaka, Andrew O'Brien, Yohan Robinson, Dachling Pang, Donald Deinlein, Sakthivel Rajaram Manoharan, Jason Pittman, and Steven Theiss.< $<$ Posttraumatic Spinal Cord Injury without Radiographic Abnormality $>>$. Hindawi Advances in Orthopedics Volume 2018, Article ID 7060654, 10 pages.

7. D.Lammertse,D.Dungan,J.Dreisbachetal., "Neuroimagin traumatic spinal cord injury: An evidence-based review for clinical practice and research," The Journal of Spinal Cord Medicine,vol.30,no.3,pp.205-214,2007.

8. M.G.HamiltonandS.T.Myles, "Pediatricspinalinjury:Review of174hospitaladmissions,"JournalofNeurosurgery,vol.77, no.5,pp.700-704,1992.

9. S.Sharma,M.Singh,I.H.Wanietal.,"AdultSpinalCordInjuryw ithoutRadiographicAbnormalities(SCIWORA):Clinicaland Radiological Correlations," Journal of Clinical Medicine Research,vol.1,no.3,pp.165-172,2009. 